\title{
A randomized comparison of right ventricular function after on-pump versus off-pump coronary artery bypass graft surgery
}

\author{
Isabelle Michaux, MD, PhD, ${ }^{\mathrm{a}, \mathrm{c}}$ Miodrag Filipovic, MD, ${ }^{\mathrm{a}}$ Karl Skarvan, MD, ${ }^{\mathrm{a}}$ Daniel Bolliger, $\mathrm{MD},{ }^{\mathrm{a}}$ \\ Regina Schumann, MD, ${ }^{a}$ Franziska Bernet, MD, ${ }^{b}$ and Manfred D. Seeberger, MD ${ }^{\mathrm{a}}$
}

\begin{abstract}
Objectives: Right ventricular dysfunction occurs very soon after conventional coronary bypass surgery with cardiopulmonary bypass and might not recover within 1 year after the operation. It has been postulated that performing coronary surgery without cardiopulmonary bypass might preserve right ventricular function. We hypothesized that right ventricular global and overall systolic functions are better preserved 3 months after off-pump surgery than after conventional coronary bypass surgery.
\end{abstract}

\begin{abstract}
Methods: Fifty patients scheduled for elective coronary bypass surgery were randomly assigned to conventional or off-pump surgery. Right ventricular function was assessed by means of transthoracic echocardiographic analysis the day before the operation and 3 months later. Right ventricular myocardial performance index was used as a marker of global right ventricular function, and right ventricular fractional area change was used as a marker of overall right ventricular systolic function. Peak systolic velocities of the lateral tricuspid annulus were studied to assess regional systolic function of the right ventricular free wall.
\end{abstract}

Results: Surgical intervention was completed according to randomization in 48 of 50 patients. Demographic and perioperative characteristics were similar in the 2 groups. Over the study period, right ventricular myocardial performance index and right ventricular fractional area change did not change in comparison with the baseline values in both groups. Peak systolic velocity of the lateral tricuspid annulus was decreased significantly in both groups 3 months after the operation. There were no significant intergroup differences in any echocardiographic marker of right ventricular function.

Conclusions: Global right ventricular function was not better preserved 3 months after off-pump surgery than after conventional coronary bypass surgery. (J Thorac Cardiovasc Surg 2011;141:361-7)

\begin{abstract}
After conventional coronary artery bypass (CCABG) surgery with cardiopulmonary bypass, right ventricular (RV) function has been found to decrease very soon after surgical intervention $^{1,2}$ and might not recover within 1 year. ${ }^{3,4}$ It has been hypothesized that avoiding cardioplegia and cardiopulmonary bypass by performing off-pump coronary artery bypass (OPCAB) surgery would reduce the damaging effects to the myocardium and thus improve outcome. ${ }^{5}$ Favorable outcome data are lacking, but a reduction in the release of cardiac enzymes after OPCAB surgery in randomized controlled trials comparing $\mathrm{CCABG}$ and $\mathrm{OPCAB}$ surgery seems to support this hypothesis. ${ }^{5,6}$ One study has shown that left ventricular (LV) systolic function is better preserved at the end of OPCAB surgery, ${ }^{6}$ but few studies

\footnotetext{
From the Department of Anesthesia, ${ }^{\text {a }}$ and the Department of Surgery, Division of Cardiothoracic Surgery, ${ }^{\mathrm{b}}$ University Hospital Basel, Basel, Switzerland; and the Department of Intensive Care Medicine, ${ }^{\mathrm{c}}$ Mont-Godinne University Hospital, Université Catholique de Louvain, Louvain-la-Neuve, Belgium.

Supported in part by the Swiss Society of Anesthesiology and Reanimation.

Disclosures: Authors have nothing to disclose with regard to commercial support.

Received for publication Oct 20, 2009; revisions received Jan 22, 2010; accepted for publication Feb 5, 2010; available ahead of print April 12, 2010.

Address for reprints: Isabelle Michaux, MD, PhD, Department of Intensive Care

Medicine, Mont-Godinne University Hospital, Université Catholique de Louvain,

B-5530 Yvoir, Belgium (E-mail: isabelle.michaux@uclouvain.be).

$0022-5223 / \$ 36.00$

Copyright (c) 2011 by The American Association for Thoracic Surgery

doi:10.1016/j.jtcvs.2010.02.023
}

have evaluated the effects of CCABG versus OPCAB surgery on RV function. Therefore we performed this randomized trial to assess and compare the effects of CCABG and OPCAB surgery on global and overall systolic RV functions 3 months after surgical intervention. Based on published studies $^{3,4}$ showing that overall systolic RV function remains impaired 3 months after CCABG surgery, we hypothesized that RV function will be better preserved 3 months after OPCAB surgery than after CCABG surgery. Two-dimensional and Doppler echocardiographic analysis was used to assess global RV function. The RV myocardial performance index (MPI) was used as an indicator of global $\mathrm{RV}$ function, RV fractional area change (FAC) was used as an indicator of overall systolic RV function, and peak systolic velocity of the lateral tricuspid annulus was used as an indicator of regional systolic function of the RV free wall.

\section{MATERIALS AND METHODS}

This prospective, randomized, controlled study was performed after approval from the Basel Committee on Human Research. Every patient provided written informed consent. Fifty consecutive patients scheduled for elective coronary artery bypass surgery and for whom the surgeon regarded off-pump and on-pump techniques as equally suitable were included. A computer-generated random list was used to assign patients to the CCABG or OPCAB groups. The randomization was performed just after the baseline transthoracic echocardiographic analysis the day before the operation Exclusion criteria were as follows: redo or emergency surgery, preoperative 


\begin{tabular}{|c|c|}
\hline \multicolumn{2}{|c|}{ Abbreviations and Acronyms } \\
\hline $\mathrm{A}_{\mathrm{a}}$ & $\begin{aligned}= & \text { Late peak diastolic velocity of the } \\
& \text { lateral tricuspid annulus }\end{aligned}$ \\
\hline CCABG & $=$ conventional coronary artery bypass \\
\hline $\mathrm{E}_{\mathrm{a}}$ & $\begin{aligned}= & \text { Early peak diastolic velocity of the } \\
& \text { lateral tricuspid annulus }\end{aligned}$ \\
\hline $\mathrm{E} / \mathrm{A}$ ratio & $\begin{aligned}= & \text { ratio of early peak diastolic velocity and } \\
& \text { late peak diastolic velocity of tricuspid } \\
& \text { inflow and mitral inflow }\end{aligned}$ \\
\hline EDA & $=$ end-diastolic area \\
\hline ESA & $=$ end-systolic area \\
\hline FAC & $=$ fractional area change \\
\hline ICU & $=$ intensive care unit \\
\hline LV & $=$ left ventricular \\
\hline MPI & $=$ myocardial performance index \\
\hline OPCAB & $=$ off-pump coronary artery bypass \\
\hline RV & $=$ right ventricular \\
\hline $\mathrm{S}_{\mathrm{a}}$ & $\begin{array}{l}=\text { peak systolic velocity of the lateral } \\
\text { tricuspid annulus }\end{array}$ \\
\hline $\mathrm{S} / \mathrm{D}$ ratio & $\begin{aligned}= & \text { ratio of systolic peak velocity and } \\
& \text { diastolic peak velocity of hepatic } \\
& \text { venous flow }\end{aligned}$ \\
\hline
\end{tabular}

hemodynamic instability requiring continuous inotropic medication, lack of sinus rhythm or complete bundle branch block or atrioventricular delay of greater than $240 \mathrm{~ms}$ on the preoperative electrocardiogram, intermittent or permanent ventricular pacing before the operation, and signs of moderate or severe mitral or tricuspid valvular disease or atrial septal defect on the preoperative transthoracic echocardiogram.

The surgical techniques were standardized, and all operations were performed by the same surgeon. CCABG surgery was performed during normothermic cardiopulmonary bypass, and antegrade cold blood cardioplegia was used for myocardial protection. OPCAB surgery was performed as described by Sergeant and associates. ${ }^{7}$ The left internal thoracic artery was consistently prepared as the only arterial graft for subsequent anastomosis either to the left anterior descending coronary artery or to a diagonal branch.

Intraoperative transesophageal echocardiographic data obtained from the patients of the present study immediately before and after coronary bypass grafting have been previously published. ${ }^{8}$

\section{Baseline Examination and Patient Follow-up}

On the day before the operation, the patients' characteristics were documented, and baseline transthoracic echocardiographic analysis was performed as described in the following paragraph. The perioperative course was obtained on daily visits with the patient, continuing until hospital discharge. New postoperative myocardial infarction was defined as a new Q wave on the 7-day electrocardiogram in association with a peak troponin level of $10 \mathrm{ng} / \mathrm{mL}$ or greater during the first 48 hours after the operation. Acute postoperative renal failure was defined as an increase in serum creatinine level of $0.5 \mathrm{mg} / \mathrm{dL}$ or greater over the baseline value during the hospital stay. Three months after the operation, all patients were contacted for prearranged transthoracic follow-up echocardiographic analysis that was performed according to a procedure identical to that used for the baseline examination. Two years after the operation, all patients were contacted by telephone for a final follow-up interview. The interview was conducted in a semistandardized fashion by a member of the study group blinded to all other data. Patients were asked about chest pain or shortness of breath or about hospitalization of any cause. In case of hospitalization, hospital charts were reviewed.

\section{Echocardiographic Recordings, Measurements, and Calculations}

The transthoracic echocardiographic studies at baseline and 3 months after the operation were performed by the same investigator using a Sonos 5500 ultrasound system and a $1.8-2.1 / 3.6-4.1 \mathrm{MHz}$ S4 probe (Philips, Best, The Netherlands). Using the respiratory signal on the screen of the imaging system, study recordings were always performed at end-expiration. Three recordings of each view were digitally acquired per study period and stored for subsequent offline analysis. The mean values of 3 measurements by a reader blinded to all other study data, including surgical technique, were used for analysis. A random sample of $25 \%$ of the data was submitted twice to the first investigator and once to a second investigator to determine intrareader and interreader variability. The variabilities were calculated as the mean absolute difference between 2 readings divided by their mean and expressed as a percentage.

Two-dimensional recordings of the apical 4-chamber view were used for measurements of RV and LV end-diastolic areas (EDAs) and end-systolic areas (ESAs). RV MPI, which is the sum of the 2 isovolumic times divided by the ejection time, was measured by means of pulsed-wave Doppler echocardiographic analysis and calculated for the right ventricle. The sum of the 2 isovolumic times was calculated by subtracting the time of RV ejection (time B) from the time between the end and onset of 2 consecutive tricuspid inflows (time A). Midesophageal 4-chamber and long-axis views were used for segmental wall motion analysis of the LV septum using the 16-segment model and the 5-grade scale of wall motion according to current guidelines. ${ }^{9}$ The presence of new septal motion abnormality at 3 months was diagnosed if wall motion in a septal segment deteriorated by 2 or more grades in comparison with baseline values, whereby the septal motion was classified as reduced. If the deterioration was less than 2 grades, the septal motion was classified as unchanged. If the septum had a systolic outward movement, it was classified as dyskinetic. The septal motion score index was calculated by dividing the sum of the scores of all readable septal segments by the number of readable segments at baseline and 3 months after the operation. Tricuspid inflow was studied in the apical 4-chamber view with the sample volume placed between the tips of the open leaflets. RV ejection time (RV time B) was measured from the parasternal short-axis view of the aortic valve after placing the pulsed-wave Doppler sample volume in the RV outflow tract. RV MPI was then calculated as follows: MPI $=($ Time $\mathrm{A}-$ Time B $) /$ Time B. Peak early and late velocities were measured, and the ratio of early peak diastolic velocity and late peak diastolic velocity of tricuspid inflow and mitral inflow (E/A ratio) was calculated. Pulsed-wave Doppler recording of the hepatic venous flow was performed from the subcostal view by placing the sample volume in the middle hepatic vein. Peak systolic and diastolic and atrial wave reversal waves were measured, and the ratio of systolic peak velocity and diastolic peak velocity of hepatic venous flow (S/D ratio) was calculated. Pulsed-wave tissue Doppler imaging was performed in the apical 4chamber view to study the motion of the lateral annulus of the tricuspid valve. Measured tissue Doppler imaging parameters included peak systolic velocity of the lateral annulus $\left(\mathrm{S}_{\mathrm{a}}\right)$ and early $\left(\mathrm{E}_{\mathrm{a}}\right)$ and late $\left(\mathrm{A}_{\mathrm{a}}\right)$ peak diastolic velocities.

Global RV function was investigated by using the RV MPI. Overall systolic RV function was investigated by using the RV FAC and calculated as follows: (RV EDA - RV ESA)/RV EDA. The regional systolic function of the lateral $R V$ free wall was investigated by using the $S_{a}$. RV diastolic function was classified as normal, mild, or moderate dysfunction based on a combined assessment proposed by Denault and colleagues, ${ }^{10}$ which considers tricuspid inflow (E/A), hepatic venous flow (S/D), and diastolic velocities of the tricuspid annulus $\left(\mathrm{E}_{\mathrm{a}}\right)$.

Global LV function was investigated by using the LV MPI, which is calculated similarly to the RV MPI, using the corresponding LV times. LV systolic function was investigated by using the LV FAC, which was calculated 
TABLE 1. Preoperative characteristics of 50 patients undergoing CCABG versus OPCAB surgery

\begin{tabular}{lcc}
\hline & $\begin{array}{c}\text { CCABG } \\
\text { group }\end{array}$ & $\begin{array}{c}\text { OPCAB } \\
\text { group }\end{array}$ \\
\hline No. of patients & 25 & 25 \\
Age (y) & $65 \pm 8$ & $61 \pm 9$ \\
Men/women & $21 / 4$ & $21 / 4$ \\
Body mass index $\left(\mathrm{kg} / \mathrm{m}^{2}\right)$ & $27 \pm 4$ & $26 \pm 3$ \\
EuroSCORE & $3.0 \pm 2.6$ & $2.4 \pm 2.5$ \\
Creatinine (mg/dL) & $0.97 \pm 0.2$ & $0.99 \pm 0.3$ \\
Three-vessel coronary artery disease & $20(80)$ & $19(76)$ \\
$>95 \%$ Stenosis of right coronary artery & $10(40)$ & $11(44)$ \\
LV ejection fraction (\%) & $58 \pm 16$ & $57 \pm 16$ \\
$\quad 330 \%$ & $2(8)$ & $3(12)$ \\
$31 \%$ to 49\% & $5(20)$ & $4(16)$ \\
$\geq 50 \%$ & $18(72)$ & $18(72)$ \\
Angina pectoris CCS III-IV & $9(36)$ & $10(40)$ \\
Prior myocardial infarction & $10(40)$ & $13(52)$ \\
Diabetes mellitus & $8(32)$ & $8(32)$ \\
Hypertension & $18(72)$ & $13(52)$ \\
Hypercholesterolemia & $18(72)$ & $20(80)$ \\
Peripheral artery disease & $3(12)$ & $2(8)$ \\
Chronic medication & & \\
$\beta$-receptor blockers & $23(92)$ & $23(92)$ \\
ACE inhibitors & $10(40)$ & $6(24)$ \\
Statins & $21(84)$ & $20(80)$ \\
Insulin & $3(12)$ & $2(8)$ \\
\hline Values are presented as means \pm standard deviations or numbers & $($ percentages). \\
Preoperative characteristics were similar in both groups. $C C A B G$, Conventional coro- & \\
nary artery bypass; $O P C A B$, off-pump coronary artery bypass; $L V$, left ventricular; & \\
CCS, Canadian Cardiovascular Society; $A C E$, angiotensin-converting enzyme. &
\end{tabular}

as follows: (LV EDA - LV ESA)/LV EDA. Mitral inflow was studied in the apical 4-chamber view with the sample volume placed between the tips of the open leaflets, early and late peak velocities were measured, and the E/A ratio was calculated.

\section{Study End Points and Statistical Analysis}

Primary end points were the echocardiographic indicators of RV global and overall systolic function (ie, MPI and FAC). A secondary end point was the $S_{a}$ as an indicator of regional systolic function of the RV free wall.

Based on a pilot study, a sample size of 25 patients per group was calculated to allow for detection of a $20 \%$ intergroup difference in the main outcome parameters RV MPI and RV FAC 3 months after surgical intervention ( $\alpha=.05$ and $\beta=.20,2$-tailed unpaired $t$ test). This sample size was also calculated to allow for detection of a $20 \%$ intergroup difference in the peak systolic velocity of the lateral tricuspid annulus $\left(\mathrm{S}_{\mathrm{a}}\right)$.

Unpaired perioperative variables are presented as medians \pm interquartile ranges and were analyzed with the Mann-Whitney $U$ test. Echocardiographic variables are presented as means \pm standard deviations and were analyzed by using the Student $t$ test. Dichotomous variables are presented as numbers and percentages, and the Fisher's exact test was used for their analysis. Analyses were performed on an intent-to-treat basis. All tests were 2-tailed. All statistical analyses were performed with the SPSS for Windows 12.0 computer package (SPSS, Inc, Chicago, Ill).

\section{RESULTS}

Surgical intervention was completed according to randomization and a standardized surgical plan in 48 of 50
TABLE 2. Postoperative characteristics of 50 patients undergoing CCABG versus OPCAB surgery

\begin{tabular}{|c|c|c|c|}
\hline & $\begin{array}{l}\text { CCABG } \\
\text { group }\end{array}$ & $\begin{array}{l}\text { OPCAB } \\
\text { group }\end{array}$ & $P$ value \\
\hline No. of patients & 25 & 25 & \\
\hline New myocardial infarction & $2(8)$ & $3(12)$ & 1.000 \\
\hline Mechanical ventilation $>12 \mathrm{~h}$ & $10(40)$ & $3(12)$ & .050 \\
\hline $\begin{array}{l}\text { Peak troponin I level in first } \\
24 \mathrm{~h} \text { after operation }\end{array}$ & $14.4(7.9-46.3)$ & $3.8(1.2-24.6)$ & .049 \\
\hline Use of intra-aortic balloon pump & $0(0)$ & $0(0)$ & \\
\hline Acute renal failure & $1(4)$ & $0(0)$ & 1.000 \\
\hline TIA & $0(0)$ & $1(4)$ & 1.000 \\
\hline Postoperative confusion & $1(4)$ & $1(4)$ & 1.000 \\
\hline Postoperative atrial fibrillation & $8(32)$ & $8(32)$ & 1.000 \\
\hline ICU readmission & $0(0)$ & $2(8)$ & .490 \\
\hline ICU stay $(\mathrm{d})$ & $2.0(2.0-2.0)$ & $1.0(1.0-1.25)$ & $<.001$ \\
\hline Hospital stay (d) & $8.0(7.0-9.0)$ & $8.0(7.0-8.0)$ & .342 \\
\hline 30-d Mortality & $0(0)$ & $0(0)$ & \\
\hline $\begin{array}{l}\text { Hospital readmission during } \\
\text { the } 3 \text { first mo }\end{array}$ & $1(4)$ & $3(12)$ & .609 \\
\hline \multicolumn{4}{|l|}{ 3-mo Medication } \\
\hline$\beta$-receptor blockers & $21(84)$ & $23(92)$ & .667 \\
\hline ACE inhibitors & $7(28)$ & $12(48)$ & .243 \\
\hline Statins & $21(84)$ & $20(80)$ & 1.000 \\
\hline 1-y Mortality & $0(0)$ & $0(0)$ & \\
\hline 2-y Mortality & $2(8)$ & $1(4)$ & 1.000 \\
\hline \multicolumn{4}{|c|}{$\begin{array}{l}\text { Values for continuous variables represent medians (interquartile ranges) compared by } \\
\text { using the nonparametric Mann-Whitney } U \text { test. Values for categorical variables are } \\
\text { presented as numbers (percentages). New myocardial infarction was defined as } \\
\text { a new } \mathrm{Q} \text { wave on the } 7 \text {-day electrocardiogram in association with a peak troponin level } \\
\text { of } 10 \mathrm{ng} / \mathrm{mL} \text { or greater during the first } 48 \text { hours after the operation. Acute postoperative } \\
\text { renal failure was defined as an increase in serum creatinine level of } 0.5 \mathrm{mg} / \mathrm{dL} \text { or } \\
\text { greater over the baseline value during the hospital stay. CCABG, Conventional } \\
\text { coronary artery bypass; } O P C A B \text {, off-pump coronary artery bypass; TIA, transient is- } \\
\text { chemic accident; } I C U \text {, intensive care unit. }\end{array}$} \\
\hline
\end{tabular}

patients. Conversion to cardiopulmonary bypass was performed in 2 of the 25 patients randomized to the OPCAB group because of marked hemodynamic instability during retraction of the heart. All patients with a significant stenosis of the right coronary artery received a venous graft to this artery, except for 6 patients whose right coronary artery was completely occluded ( 2 in the CCABG group and 4 in the OP$\mathrm{CAB}$ group). A significant stenosis of the $\mathrm{RV}$ branch was observed in 4 patients ( 2 in the CCABG group and 2 in the OPCAB group). These RV branches were not revascularized because they were regarded as too small $(<1.5 \mathrm{~mm})$ to receive a bypass graft.

\section{General Characteristics}

The 2 groups had similar demographic and perioperative characteristics (Tables 1 and 2). No patient had a previously documented RV infarction or pulmonary hypertension. Seven patients had a slow initial recovery and remained in the intensive care unit (ICU) more than 48 hours (4 in the $\mathrm{CCABG}$ group and 3 in the OPCAB group). Two patients in the OPCAB group were readmitted to the ICU 


\section{CCABG Group}
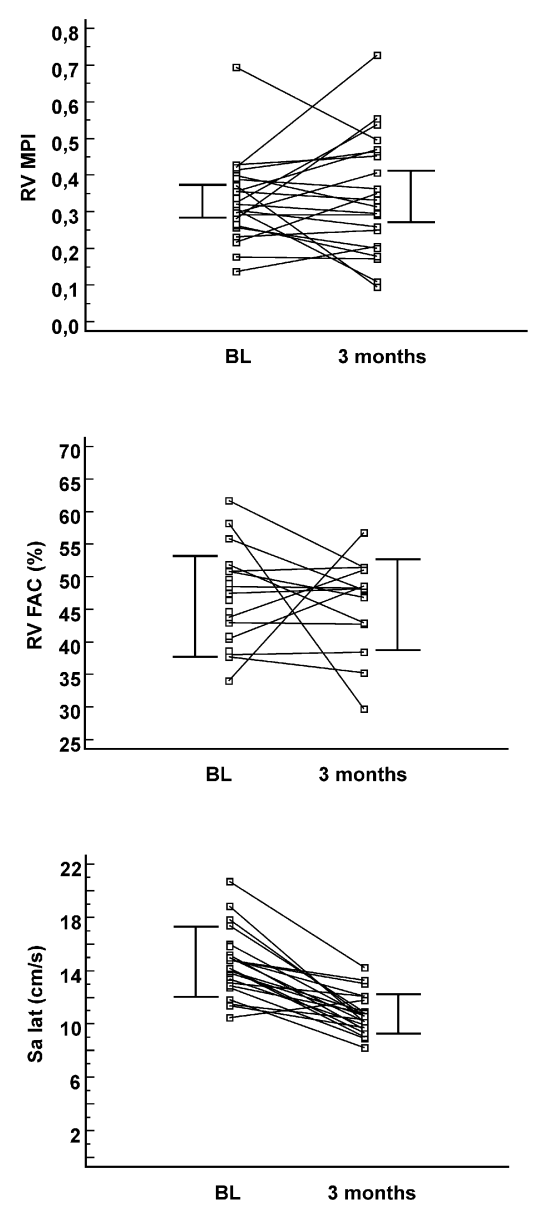

\section{OPCAB Group}
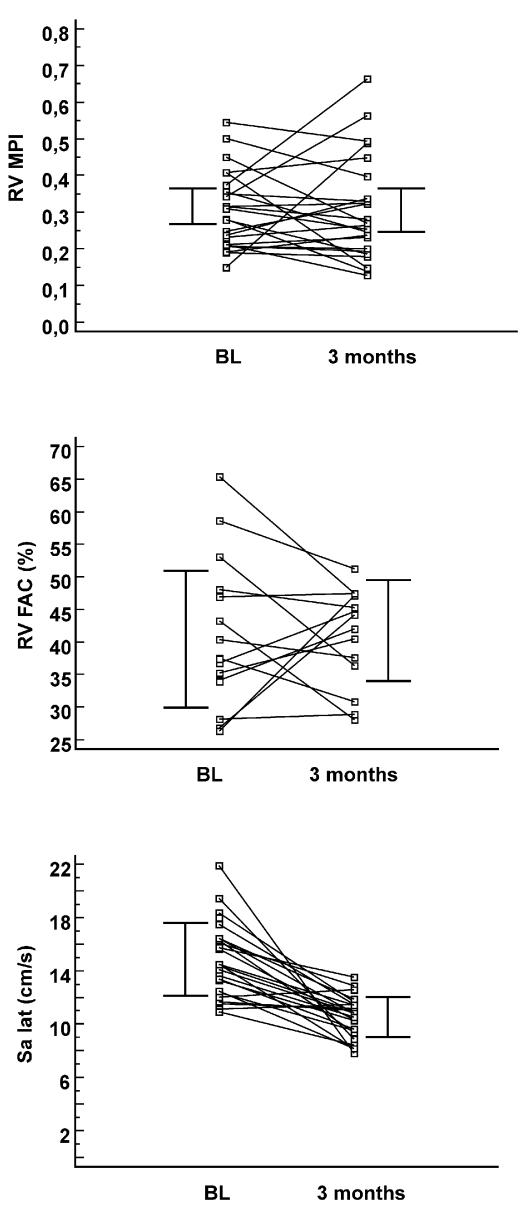

FIGURE 1. Echocardiographic parameters of global and systolic right ventricular functions at baseline and 3 months after surgical intervention in 25 patients undergoing conventional on-pump coronary bypass surgery $(C C A B G)$ versus 25 patients undergoing off-pump coronary bypass surgery $(O P C A B)$. $R V$, Right ventricular; $M P I$, myocardial performance index; $B L$, baseline; $F A C$, fractional area change; $S_{a}$, peak systolic velocity of the lateral tricuspid annulus.

because of respiratory failure, and 1 was reintubated. However, there were no major adverse events, and the 30 -day mortality rate was 0 in both groups. During the 3 month follow-up period, 1 patient in the CCABG group and 3 patients in the OPCAB group were readmitted to the hospital. The patient in the CCABG group was hospitalized because of perirenal hematoma. In the OPCAB group 1 patient was hospitalized because of recurring angina caused by a nongrafted right coronary artery (occluded at the time of the operation; all grafts were patent), 1 patient because of ventricular tachycardia (all grafts were patent), and 1 patient because of Dressler syndrome. At the time of the 2-year follow-up, 2 patients in the CCABG group and 1 patient in the OPCAB group had died: 1 patient in the CCABG group from acute lung embolism after orthopedic surgery, as determined by autopsy; another patient in the CCABG group from suicide; and 1 patient in the OPCAB group from progression of chronic lung fibrosis resulting in acute respiratory failure.

\section{Echocardiographic Findings}

For more information on echocardiographic findings, see Figure 1 and Tables 3 to 5. Baseline examinations were performed in all patients. Four patients refused the 3month transthoracic echocardiographic follow-up (3 in the CCABG group and 1 in the OPCAB group). Three months after the operation, RV MPI and RV FAC values were unchanged in comparison with baseline values in both groups. $\mathrm{S}_{\mathrm{a}}$ was significantly decreased in both groups 3 months after the operation. There were further changes in diastolic RV echocardiographic parameters between the baseline and follow-up study but no differences between the 2 groups at either time point: increased $\mathrm{E} / \mathrm{A}, \mathrm{S} / \mathrm{D}$, and $\mathrm{E}_{\mathrm{a}} / \mathrm{A}_{\mathrm{a}}$; decreased $A_{a}$; and increased $E_{a}$ that reached statistical significance in the CCABG group only. LV echocardiographic findings 3 months after the operation were similar in both groups: LV MPI was not markedly changed, and LV FAC and LV EDA were increased in both groups. Reduced septal motion was observed in 6 and 7 patients in the CCABG and OPCAB 
TABLE 3. Hemodynamic and echocardiographic parameters in 50 patients undergoing CCABG versus OPCAB surgery

\begin{tabular}{|c|c|c|c|c|c|}
\hline & \multicolumn{2}{|c|}{ CCABG group } & \multicolumn{2}{|c|}{ OPCAB group } & \multirow{2}{*}{$\begin{array}{c}\text { Intergroup comparison } \\
P \text { value } \\
\end{array}$} \\
\hline & Baseline & $3 \mathrm{mo}$ & Baseline & $3 \mathrm{mo}$ & \\
\hline \multicolumn{6}{|l|}{ Hemodynamics } \\
\hline Heart rate (beats/min) & $62 \pm 7$ & $66 \pm 10^{*}$ & $64 \pm 12$ & $65 \pm 10$ & .836 \\
\hline \multicolumn{6}{|c|}{ Right ventricular parameters } \\
\hline MPI & $0.33 \pm 0.11$ & $0.34 \pm 0.16$ & $0.32 \pm 0.11$ & $0.31 \pm 0.14$ & .411 \\
\hline FAC $(\%)$ & $45 \pm 8$ & $46 \pm 7$ & $40 \pm 11$ & $42 \pm 8$ & .180 \\
\hline $\operatorname{EDA}\left(\mathrm{cm}^{2}\right)$ & $19 \pm 4$ & $20 \pm 3$ & $19 \pm 4$ & $20 \pm 4$ & .762 \\
\hline $\operatorname{ESA}\left(\mathrm{cm}^{2}\right)$ & $10 \pm 3$ & $11 \pm 3$ & $12 \pm 3$ & $12 \pm 2$ & .415 \\
\hline $\mathrm{E} / \mathrm{A}$ & $1.1 \pm 0.3$ & $1.4 \pm 0.3^{*}$ & $1.2 \pm 0.3$ & $1.4 \pm 0.3 \ddagger$ & .789 \\
\hline $\mathrm{S} / \mathrm{D}$ & $1.8 \pm 0.4$ & $1.2 \pm 0.3 \ddagger$ & $1.8 \pm 0.4$ & $1.2 \pm 0.3 \ddagger$ & .711 \\
\hline $\operatorname{Ar}(\mathrm{cm} / \mathrm{s})$ & $23 \pm 7$ & $22 \pm 11$ & $23 \pm 7$ & $22 \pm 8$ & .775 \\
\hline $\mathrm{S}_{\mathrm{a}}(\mathrm{cm} / \mathrm{s})$ & $14.7 \pm 2.7$ & $10.7 \pm 1.5 \ddagger$ & $14.9 \pm 2.8$ & $10.5 \pm 1.5 \ddagger$ & .657 \\
\hline $\mathrm{E}_{\mathrm{a}}(\mathrm{cm} / \mathrm{s})$ & $10.8 \pm 3.0$ & $8.4 \pm 1.9 \dagger$ & $10.6 \pm 3.3$ & $9.7 \pm 3.1$ & .097 \\
\hline $\mathrm{A}_{\mathrm{a}}(\mathrm{cm} / \mathrm{s})$ & $17.1 \pm 3.5$ & $10.4 \pm 2.6 \ddagger$ & $16.9 \pm 3.7$ & $9.6 \pm 1.6 \ddagger$ & .232 \\
\hline $\mathrm{E}_{\mathrm{a}} / \mathrm{A}_{\mathrm{a}}$ & $0.6 \pm 0.1$ & $0.9 \pm 0.3 \dagger$ & $0.7 \pm 0.2$ & $1.0 \pm 0.3 \ddagger$ & .218 \\
\hline \multicolumn{6}{|l|}{ Left ventricular parameters } \\
\hline MPI & $0.52 \pm 0.18$ & $0.46 \pm 0.19$ & $0.51 \pm 0.17$ & $0.48 \pm 0.13$ & .659 \\
\hline FAC $(\%)$ & $32 \pm 10$ & $48 \pm 12 \ddagger$ & $33 \pm 10$ & $44 \pm 11 \ddagger$ & .788 \\
\hline $\operatorname{EDA}\left(\mathrm{cm}^{2}\right)$ & $15 \pm 4$ & $18 \pm 5 \ddagger$ & $14 \pm 4$ & $18 \pm 5 \ddagger$ & .971 \\
\hline ESA $\left(\mathrm{cm}^{2}\right)$ & $10 \pm 3$ & $10 \pm 4$ & $10 \pm 4$ & $10 \pm 4$ & .755 \\
\hline $\mathrm{E} / \mathrm{A}$ & $0.8 \pm 0.3$ & $1.0 \pm 0.3$ & $0.8 \pm 0.3$ & $0.9 \pm 0.3^{*}$ & .282 \\
\hline WMSI-septum & $1.6 \pm 0.8$ & $2.0 \pm 0.9 \ddagger$ & $1.6 \pm 0.7$ & $2.0 \pm 0.8 \ddagger$ & 1.000 \\
\hline
\end{tabular}

Values are presented as means \pm standard deviations. $C C A B G$, Conventional coronary artery bypass; $O P C A B$, off-pump coronary artery bypass; $M P I$, myocardial performance index; $F A C$, fractional area change; $E D A$, end-diastolic area; $E S A$, end-systolic area; $E / A$, ratio of early peak diastolic velocity and late peak diastolic velocity of tricuspid inflow and mitral inflow, respectively; $S / D$, ratio of systolic peak velocity and diastolic peak velocity of hepatic venous flow; $A r$, atrial wave reversal of hepatic venous flow; $S_{a}$, peak systolic velocity of the lateral tricuspid annulus; $E_{a}$, early peak diastolic velocity of the lateral tricuspid annulus; $A_{a}$, late peak diastolic velocity of the lateral tricuspid annulus; $W M S I-$ septum, wall motion score indices for the 5 septal segments. ${ }^{*} P \leq .05$ in comparison with baseline values (paired $t$ test); $\dagger \mathrm{P} \leq .01$ in comparison with baseline values (paired $t$

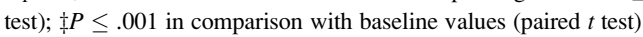

groups, respectively, and dyskinetic motion was observed in 2 and 1 patients in the CCABG and OPCAB groups, respectively (Table 5). There were no intergroup differences in the septal motion score index, although the septal motion score index increased significantly in both groups at 3 months.

The high reproducibility of LV echocardiographic measurements performed by our group has been previously documented. ${ }^{11}$ In the present study intrareader variability for RV echocardiographic measurements ranged from $2 \%$ $\left(\mathrm{S}_{\mathrm{a}}\right)$ to $7 \%$ (RV FAC), and interreader variability ranged from $4 \%\left(S_{a}\right)$ to $8 \%(R V$ MPI).

\section{DISCUSSION}

This randomized controlled study found that global and overall systolic RV functions were not better preserved 3 months after OPCAB surgery than after CCABG surgery: all echocardiographic indicators of RV function were similar in the 2 study groups. Global and overall systolic RV function, as indicated by RV MPI and RV FAC, were preserved in both groups 3 months after surgical intervention.

In contrast, analysis of $S_{a}$ revealed similarly impaired regional systolic function in both groups. Although this parameter has been used as a marker of overall systolic RV function, ${ }^{12,13}$ it can be markedly determined by regional systolic function of the RV free wall. This conflicting observation of a preserved global RV function in the presence of reduced systolic tricuspid annular velocities was also made by Hedman and colleagues. ${ }^{4}$ They observed improved exercise performance in their patients 3 months after CCABG surgery, despite reduced tricuspid annular velocities, and concluded that the reduction in tricuspid velocities lacked clinical significance. Reduced systolic tricuspid annular velocities were also observed by Alam and coworkers ${ }^{3} 3$ months and 1 year after uncomplicated CCABG surgery.

TABLE 4. Classification of right ventricular diastolic dysfunction in 50 patients undergoing CCABG versus OPCAB surgery

\begin{tabular}{ccccccccr}
\hline & \multicolumn{3}{c}{ CCABG group } & & \multicolumn{3}{c}{ OPCAB group } \\
\cline { 2 - 4 } & Normal & Mild & Moderate & & Normal & Mild & Moderate & $P$ value* \\
\hline Baseline & 1 & 24 & 0 & 0 & 25 & 0 & 1.000 \\
3 mo & 5 & 12 & 5 & 8 & 13 & 3 \\
\hline
\end{tabular}

$C C A B G$, Conventional coronary artery bypass; $O P C A B$, off-pump coronary artery bypass. *Extended Fisher exact test. 
TABLE 5. Septal motion abnormalities 3 months after surgical intervention in comparison with baseline values in 50 patients undergoing CCABG versus OPCAB surgery

\begin{tabular}{|c|c|c|c|c|c|c|}
\hline \multicolumn{3}{|c|}{ CCABG group } & \multicolumn{3}{|c|}{ OPCAB group } & \multirow[b]{2}{*}{$P$ value* } \\
\hline Unchanged & Reduced & Dyskinetic & Unchanged & Reduced & Dyskinetic & \\
\hline 14 & 6 & 2 & 16 & 7 & 1 & .899 \\
\hline
\end{tabular}

$C C A B G$, Conventional coronary artery bypass; $O P C A B$, off-pump coronary artery bypass; Unchanged, deterioration of the septal motion score index by less than 2 grades; Reduced, deterioration of the septal motion score index by 2 or more grades; Dyskinetic, systolic outward motion of the septum. *Extended Fisher's exact test.

As a cause for this finding, they discussed postoperative pericardial adhesions that were previously proposed as an explanation for restricted tricuspid annular motion after cardiac surgery. ${ }^{1,2}$ Interestingly, systolic and diastolic interventricular septal velocities were preserved in their patients. All these observations and our own findings are consistent with experimental and animal studies identifying the interventricular septum as the key structure for global and systolic RV function. ${ }^{14-16}$ Finally, the left ventricle contributes to RV function through the mechanism of ventricular interdependence. ${ }^{17}$ Therefore the improved LV systolic function observed in both of our study groups might have contributed to preserving RV systolic function despite deteriorated systolic function of the RV free wall.

The findings of the present study are in agreement with the follow-up data of a recently published study on the effects of OPCAB versus CCABG surgery on RV function. ${ }^{18}$ These authors used magnetic resonance imaging and found that $\mathrm{RV}$ function was completely recovered in both groups 6 months after surgical intervention. Early after surgical intervention, however, they found similarly impaired RV ejection fraction in both groups. This latter finding differs from our previously published intraoperative transesophageal echocardiographic findings in the same study groups (ie, similarly preserved $\mathrm{RV}$ ejection fraction in both groups at the end of surgery). ${ }^{8}$ Unlike in other studies, we did not perform an additional early follow-up study before patient discharge, which keeps us from excluding a transient decrease in RV ejection fraction in the early postoperative period.

The evaluation of RV diastolic function is not clearly defined in the literature. Some authors have tried to evaluate it based on the combination of tricuspid E/A ratio, hepatic S/D ratio, and $\mathrm{E}_{\mathrm{a}} \cdot{ }^{10,19}$ Using an algorithm proposed by Denault and associates, ${ }^{10}$ we found a similar proportion of patients with normal, mildly, and moderately impaired RV diastolic function in the 2 groups 3 months after the operation (Table 4 ).

The sample size of this study was not designed to detect differences in the postoperative course between the 2 groups. Our finding of a shorter length of ICU stay in the OPCAB group is biased by our local routine procedure to keep the patients undergoing CCABG a minimum of 48 hours in the ICU, whereas patients undergoing OPCAB with an uncomplicated course are discharged from the ICU after 24 hours. The patients undergoing CCABG were more likely than the patients undergoing OPCAB to be ventilated for more than 12 hours $(40 \%$ vs $12 \%$, $P=.05)$. A shorter ventilation time after OPCAB surgery was found in some studies ${ }^{20,21}$ but was not confirmed by recent randomized studies. ${ }^{22,23}$

The present study has some limitations. Our conclusions are based on an intent-to-treat analysis, and 2 patients who were converted from $\mathrm{OPCAB}$ surgery to $\mathrm{CCABG}$ surgery were analyzed in the OPCAB group. However, an astreated analysis would not have changed the result because the 2 groups were similar and the 2 patients were not outliers.

Another limitation is the presence of right coronary artery disease in the large majority of our patients, which complicates the interpretation of the respective roles of surgical technique and ischemia on RV function. However, this limitation similarly applies to both groups. Recruitment of patients with left coronary artery disease alone is not feasible because the cardiologists currently treat them with angioplasty.

The lack of tissue Doppler imaging data for the interventricular septum is another limitation because the septum plays a key role in RV function. ${ }^{14}$ However, similarly impaired regional septal wall motion in the 2 study groups (Tables 3 and 5) suggests that OPCAB and CCABG surgery similarly affect interventricular septal function. All of our patients undergoing CCABG received blood cardioplegia. This complicates the extrapolation of our findings to crystalloid cardioplegia, which might not provide the same degree of myocardial protection. ${ }^{24,25}$

Another limitation is that the echocardiographic followup was restricted to 3 months. This prevents us from making conclusions about a potential long-term recovery of the function of the RV free wall as indicated by tricuspid annular velocities. A final limitation is the sample size that was calculated to allow for the analysis of echocardiographic parameters of RV function but is clearly too low to allow for the analysis of outcome parameters.

In conclusion, our study found that RV function was no better preserved after OPCAB surgery than after CCABG surgery. Global and overall systolic RV functions were equally preserved 3 months after OPCAB and CCABG surgery. The analysis of the lateral tricuspid annular velocities suggested persistently impaired systolic myocardial function at the level of the RV free wall in both groups. Global LV function was equally preserved, and LV systolic function 
was similarly improved in both groups 3 months after surgical intervention.

We thank Esther Seeberger and Claudia Werner, Department of Anesthesia, University Hospital Basel, for help with data acquisition and Allisson Dwileski, Department of Anesthesia University Hospital Basel, for editorial assistance. We also thank Jacques Jamart, Department of Biostatistics, University Clinics of Mont Godinne, Université Catholique de Louvain, Yvoir, Belgium, for statistical assistance.

\section{References}

1. Mishra M, Swaminathan M, Malhotra R, Mishra A, Trehan N. Evaluation of right ventricular function during CABG: transesophageal echocardiographic assessment of hepatic venous flow versus conventional right ventricular performance indices. Echocardiography. 1998;15:51-8.

2. Wranne B, Pinto FJ, Hammarstrom E, St Goar FG, Puryear J, Popp RL. Abnormal right heart filling after cardiac surgery: time course and mechanisms. Br Heart J. 1991;66:435-42.

3. Alam M, Hedman A, Nordlander R, Samad B. Right ventricular function before and after an uncomplicated coronary artery bypass graft as assessed by pulsed wave Doppler tissue imaging of the tricuspid annulus. Am Heart J. 2003;146: 520-6.

4. Hedman A, Alam M, Zuber E, Nordlander R, Samad BA. Decreased right ventricular function after coronary artery bypass grafting and its relation to exercise capacity: a tricuspid annular motion-based study. J Am Soc Echocardiogr. 2004; 17: 126-31.

5. Puskas JD, Williams WH, Duke PG, Staples JR, Glas KE, Marshall JJ, et al. Offpump coronary artery bypass grafting provides complete revascularization with reduced myocardial injury, transfusion requirements, and length of stay: a prospective randomized comparison of two hundred unselected patients undergoing off-pump versus conventional coronary artery bypass grafting. J Thorac Cardiovasc Surg. 2003;125:797-808.

6. Selvanayagam JB, Petersen SE, Francis JM, Robson MD, Kardos A, Neubauer S, et al. Effects of off-pump versus on-pump coronary surgery on reversible and irreversible myocardial injury: a randomized trial using cardiovascular magnetic resonance imaging and biochemical markers. Circulation. 2004;109:345-50.

7. Sergeant P, de Worm E, Meyns B, Wouters P. The challenge of departmental quality control in the reengineering towards off-pump coronary artery bypass grafting. Eur J Cardiothorac Surg. 2001;20:538-43.

8. Michaux I, Filipovic M, Skarvan K, Schneiter S, Schumann R, Zerkowski HR, et al. Effects of on-pump versus off-pump coronary artery bypass graft surgery on right ventricular function. J Thorac Cardiovasc Surg. 2006;131:1281-8.

9. Shanewise JS, Cheung AT, Aronson S, Stewart WJ, Weiss RL, Mark JB, et al. ASE/SCA guidelines for performing a comprehensive intraoperative multiplane transesophageal echocardiography examination: recommendations of the American Society of Echocardiography Council for Intraoperative Echocardiography and the Society of Cardiovascular Anesthesiologists Task Force for Certification in Perioperative Transesophageal Echocardiography. Anesth Analg. 1999;89: 870-84.
10. Denault AY, Couture P, Buithieu J, Haddad F, Carrier M, Babin D, et al. Left and right ventricular diastolic dysfunction as predictors of difficult separation from cardiopulmonary bypass [La dysfonction ventriculaire diastolique gauche et droite comme predicteur des difficultes de sevrage de la circulation extracorporelle]. Can J Anesth. 2006;53:1020-9.

11. Filipovic M, Wang J, Michaux I, Hunziker P, Skarvan K, Seeberger MD. Effects of halothane, sevoflurane and propofol on left ventricular diastolic function in humans during spontaneous and mechanical ventilation. Br J Anaesth. 2005;94: 186-92.

12. Miller D, Farah MG, Liner A, Fox K, Schluchter M, Hoit BD. The relation between quantitative right ventricular ejection fraction and indices of tricuspid annular motion and myocardial performance. J Am Soc Echocardiogr. 2004;17:443-7.

13. Wang J, Prakasa K, Bomma C, Tandri H, Dalal D, James C, et al. Comparison of novel echocardiographic parameters of right ventricular function with ejection fraction by cardiac magnetic resonance. J Am Soc Echocardiogr. 2007;20: 1058-64.

14. Buckberg GD, Restore Group R. The ventricular septum: the lion of right ventricular function, and its impact on right ventricular restoration. Eur J Cardiothorac Surg. 2006;29:S272-8.

15. Sawatani S, Mandell G, Kusaba E, Schraut W, Cascade P, Wajszczuk WJ, et al. Ventricular performance following ablation and prosthetic replacement of right ventricular myocardium. Trans Am Soc Artif Intern Organs. 1974;20B:629-36.

16. Starr I, Jeffers W, Meade R Jr. The absence of conspicuous increments of venous pressure after severe damage to the right ventricle of the dog, with a discussion of the relation between clinical congestive failure and heart disease. Am Heart J. 1943;26:291-301.

17. Yamaguchi S, Harasawa H, Li KS, Zhu D, Santamore WP. Comparative significance in systolic ventricular interaction. Cardiovasc Res. 1991;25:774-83.

18. Pegg TJ, Selvanayagam JB, Karamitsos TD, Arnold RJ, Francis JM, Neubauer S, et al. Effects of off-pump versus on-pump coronary artery bypass grafting on early and late right ventricular function. Circulation. 2008;117:2202-10.

19. Shi Y, Denault AY, Couture P, Butnaru A, Carrier M, Tardif JC. Biventricular diastolic filling patterns after coronary artery bypass graft surgery. $J$ Thorac Cardiovasc Surg. 2006;131:1080-6.

20. Al-Ruzzeh S, Ambler G, Asimakopoulos G, Omar RZ, Hasan R, Fabri B, et al. Off-pump coronary artery bypass (OPCAB) surgery reduces risk-stratified morbidity and mortality: a United Kingdom multi-center comparative analysis of early clinical outcome. Circulation. 2003;108(suppl 1):II1-8.

21. Straka Z, Brucek P, Vanek T, Votava J, Widimsky P. Routine immediate extubation for off-pump coronary artery bypass grafting without thoracic epidural analgesia. Ann Thorac Surg. 2002;74:1544-7.

22. Gerola LR, Buffolo E, Jasbik W, Botelho B, Bosco J, Brasil LA, et al. Off-pump versus on-pump myocardial revascularization in low-risk patients with one or two vessel disease: perioperative results in a multicenter randomized controlled trial Ann Thorac Surg. 2004;77:569-73.

23. Straka Z, Widimsky P, Jirasek K, Stros P, Votava J, Vanek T, et al. Off-pump versus on-pump coronary surgery: final results from a prospective randomized study PRAGUE-4. Ann Thorac Surg. 2004;77:789-93.

24. Christakis GT, Buth KJ, Weisel RD, Rao V, Joy L, Fremes SE, et al. Randomized study of right ventricular function with intermittent warm or cold cardioplegia. Ann Thorac Surg. 1996;61:128-34.

25. Bert AA, Singh AK. Right ventricular function after normothermic versus hypothermic cardiopulmonary bypass. J Thorac Cardiovasc Surg. 1993;106:988-96. 